\title{
USE OF LANDSAT-8 OLI IMAGERY AND LOCAL INDIGENOUS KNOWLEDGE FOR EELGRASS MAPPING IN EEYOU ISTCHEE
}

\author{
K. Clyne ${ }^{1, *}$, B. Leblon ${ }^{1}$, A. LaRocque ${ }^{1}$, M. Costa ${ }^{2}$, M. Leblanc ${ }^{3}$, E. Rabbitskin ${ }^{4}$, M. Dunn ${ }^{4}$ \\ ${ }^{1}$ University of New Brunswick, Fredericton (NB), Canada; (kclyne, bleblon, larocque)@unb.ca \\ ${ }^{2}$ University of Victoria, Victoria (BC), Canada; maycira@uvic.ca \\ ${ }^{3}$ McGill University, Ste-Anne-de-Bellevue (QC); melanie-louise.leblanc@mail.mcgill.ca \\ ${ }^{4}$ Niskamoon Corporation, Nemaska (QC); (erabbitskin, mdunn)@ niskamoon.org
}

\section{Commission I, ICWG I/II}

KEY WORDS: Eelgrass mapping, James Bay, Landsat-8, Random Forests, local indigenous knowledge, Cree territory

\begin{abstract}
:
The eastern coastline of James Bay (Eeyou Istchee) is known to be home to beds of subarctic eelgrass (Zostera marina L.). These eelgrass beds provide valuable habitat and food source for coastal and marine animals and contribute valuable ecosystem services such as stabilization of the shoreline all along the coast. Despite reports from Cree communities that eelgrass bed health has declined, limited research has been performed to assess and map the spatial distribution of eelgrass within the bay. This study aims to address that issue by evaluating the capability of Landsat-8 Operational Land Imager (OLI) imagery to establish a baseline map of eelgrass distribution in 2019 in the relatively turbid waters of Eeyou Istchee. Three images acquired in September 2019 were merged and classified using Random Forests into the following classes: Eelgrass, Turbid Water, Highly Turbid Water, and Optically Deep Water. The resulting classified image was validated against 108 ground truth data that were obtained from both the eelgrass health and Hydro-Quebec research team. The resulting overall accuracy was $78.7 \%$, indicating the potential of the Random Forests classifier to estimate baseline eelgrass coverage in James Bay using Landsat-8 imagery. This project is part of a Cree driven project, the Coastal Habitat Comprehensive Research Program (CHCRP). The CHCRP aims to combine Cree's traditional knowledge with Western science to better understand environmental changes in the coastal ecosystems and ecosystem services of eastern James Bay. The study is funded by a MITACS grant sponsored by Niskamoon Corporation, an indigenous non-profit organization.
\end{abstract}

\section{INTRODUCTION}

Zostera marina L., more commonly known as eelgrass, is a marine flowering plant found in a wide range of coastal marine environments across the Northern Hemisphere (Murphy et al., 2011). It occurs primarily in the sublittoral zone, in areas sheltered from wave action with a soft or sandy substrate and is generally submerged at low tide (DFO, 2009). Seagrasses, including eelgrass, provide a wide variety of ecosystem services, which make them an important indicator of environmental health (Bos et al., 2007; Wong et al., 2013). Some of the services they provide include protection from wave and tidal action, shelter for juvenile fish and invertebrates (Joseph et al., 2013; Kennedy et al., 2018), carbon sequestration (Macreadie et al., 2014), and a foraging environment for migratory and/or residential waterfowl (Seymour et al., 2002; Kollars et al., 2017). Seagrasses can also play an important role in sediment stabilization and erosion reduction (Potouroglou et al., 2017), making it an important feature for coastline preservation (Waycott et al., 2009).

The Eastern coastline of James Bay, Quebec (also referred to as Eeyou Istchee by the Cree First Nation) offers an excellent growing environment for eelgrass (Lalumière et al., 1994). The coastline is dotted with numerous islands providing shelter from wind and wave action (Martini, 1986), and coastal development by humans is low. In Eeyou Istchee, eelgrass beds are critical food for waterfowl (Nienhuis, Groenendijk, 1986), particularly for the Canada Geese (Branta canadensis) and Atlantic Brant (B. bernicla rota), as documented by the Cree hunter experience and described in Dignard et al. (1991), COMEX (2013), and Royer (2016). To this day, migratory waterfowl hunting is an important ${ }^{1}$ activity in coastal communities and contributes to maintaining traditional food security.

Eeyou Istchee has been subject to climate change and large-scale hydroelectric development in the past fifty years. Hydroelectric development in the eastern James Bay watershed, which began in the 1970s, has entailed diverting water from the Ungava Bay watershed and the Rupert and Eastmain Rivers of southern James Bay into the La Grande River watershed that drains into northeast James Bay. Although the coastal zones have been monitored since the early 1980s, many of the hydrological changes and implications for eelgrass distribution within the bay are largely understudied. The Cree Land Users of Eeyou-Istchee have noted steady declines in eelgrass coverage along the coast especially near Chisasibi in the late 1980 s, and then a drastic decline in 1997-1998 (Consortium Genivar Waska, 2017). Cree report that since the decline in the late $1990 \mathrm{~s}$, recovery of the eelgrass has been very slow, and the eelgrass currently observed in some areas seems unhealthy (e.g. shorter, less dense, discoloured) (Consortium Genivar Waska, 2017)

Due to the inaccessibility of much of the coastline, quantifying and mapping eelgrass extent within the bay presents a major challenge. Multispectral satellite imagery offers the only source of continuous data spanning the entire extent of the coastline, and much of it is freely available. The objectives of this study are to assess the capability of the Landsat- 8 Operational Land Imager

\footnotetext{
${ }^{*}$ Corresponding author
} 
(OLI) imagery to detect eelgrass in Eeyou Istchee waters, as well as to assess and map the distribution of eelgrass along the eastern coastline of James Bay in the summer of 2019. Temperate and subarctic water, such as in Eeyou Istchee, poses additional challenges for mapping eelgrass compared to tropical and subtropical waters because this region tends to have lower water clarity, and therefore low light penetration, like West coast waters (O’Neill, Costa, 2013, Reshitnyk et al., 2014). Local indigenous knowledge about the eelgrass beds was employed during field data collection. The study is part of a Cree driven project, the Coastal Habitat Comprehensive Research Program (CHCRP), which aims to combine Cree traditional knowledge with Western science to better understand environmental changes in the coastal ecosystems and ecosystem services of eastern James Bay.

\section{MATERIALS AND METHODS}

\subsection{Study area}

The study area encompasses the entire Eastern coastline of James Bay, from about $54.7^{\circ} \mathrm{N}$ latitude in the north to $51.1^{\circ} \mathrm{N}$ in the south (Figure 1). James Bay represents the southernmost portion of Hudson Bay. Eastern James Bay is ice-covered between December and early June each year (El-Sabh, Koutitonsky, 1977), although the date of fast ice breakup has gotten progressively earlier since 1980 (Taha et al., 2019).

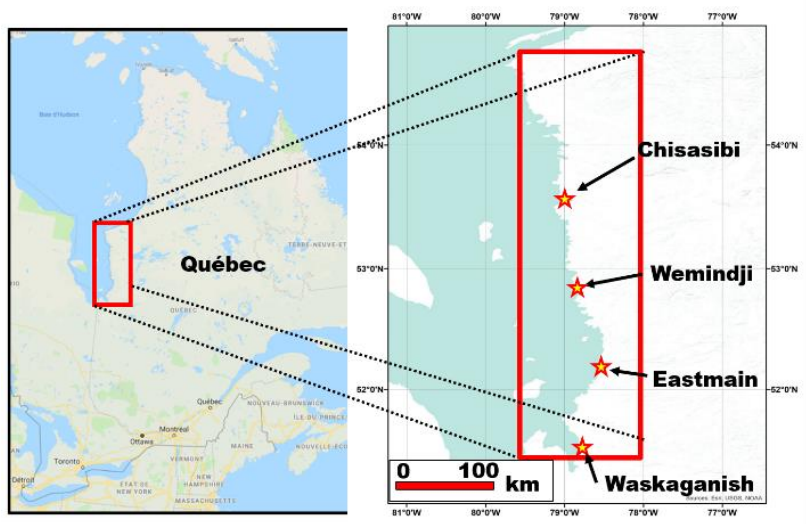

Figure 1. Location the four main Cree coastal communities along the Western coastline of Eeyou-Istchee.

James Bay is essentially a postglacial depression, and as such is affected by the isostatic rebound. Thus, the eastern coastline can be characterized by having a low coastal slope and many islands that dot the shoreline, protecting it from wind and tidal action. According to Dignard et al. (1991), eelgrass meadows are abundant in every inlet along the eastern coast of James Bay, except at the mouth of large rivers. Towards the open sea, eelgrass meadows generally are replaced by a zone colonized by Fucus distichus and Ascophyllum nodosum (Dignard et al., 1991). Four coastal communities, namely Chisasibi, Wemindji, Eastmain, and Waskaganish, with populations (mostly Cree First Nations) ranging from about 900 people in Eastmain to nearly 5000 people in Chisasibi, are located along this coast. Except for the hydroelectric development initiated in the early 1970s (Marsh, 2015), there is little coastal development in the region.

\subsection{Image Acquisition}

The study used freely available imagery acquired by the Landsat8 Operational Land Imager (OLI) (Table 1). Images were obtained on the United States Geological Survey's (USGS) Earth Explorer website. Three images were acquired on September 16, 2019 , during the period where the eelgrass was reached its peak biomass (Lalumière et al., 1994). Given that there was cloud cover over Chisasibi on the September image, we used a cloudfree image which was acquired on August 26, 2019, as close as possible to the September image.

\begin{tabular}{|c|c|c|c|}
\hline Scene Identifier & $\begin{array}{c}\text { Image } \\
\text { Date }\end{array}$ & $\begin{array}{c}\text { Image } \\
\text { Time } \\
\text { (UTC) }\end{array}$ & $\begin{array}{c}\text { Tide } \\
\text { Height } \\
\text { (m) }\end{array}$ \\
\hline LC80200222019259LGN00 & $2019-09-16$ & $16: 12: 59$ & 1.1 \\
LC80200232019259LGN00 & $2019-09-16$ & $16: 13: 23$ & 1.1 \\
LC80200242019259LGN00 & $2019-09-16$ & $16: 13: 47$ & 1.1 \\
LC80210222019234LGN00 & $2019-08-22$ & $16: 19: 19$ & 1.4 \\
\hline
\end{tabular}

Table 1. List of the Landsat-8 OLI images acquired from the USGS EarthExplorer website for use in the study.

\subsection{Field data}

Field data were acquired during the summer of 2019 from two different sources: Hydro-Quebec's eelgrass monitoring program (Hydro-Québec: Englobe corporation, 2019) and the CHCRP's field surveys (O'Connor et al., 2019) (Table 2). Both datasets evaluated eelgrass presence/absence at several sites throughout the study area that was determined using snorkeling surveys by SCUBA divers and snorkelling divers of the CHCRP eelgrass health team and Hydro-Québec. The location of the sites assess by the CHCRP dataset was guided by local Cree land users who have a good understanding of their coastal environment. Each dataset recorded each point's location using a GPS. The CHCRP dataset from the field research team was scored into two classes: eelgrass present and eelgrass absent. The Hydro-Quebec dataset scored eelgrass density at each site on a scale from 1-4, with 4 representing continuous eelgrass and 1 representing a complete absence of eelgrass. To compare the two datasets, any score from 2-4 in the Hydro-Quebec dataset was considered eelgrass present. These field data were used to validate the final classified image mosaic. Points that were classified as turbid water were omitted from the validation analysis, since the reflectance signal in turbid waters is dominated by particulate matter in the water column, and therefore should not show the spectral signature of eelgrass.

\begin{tabular}{|l|c|c|c|c|}
\hline Dataset & $\begin{array}{c}\text { Eelgrass } \\
\text { Present }\end{array}$ & $\begin{array}{c}\text { Eelgrass } \\
\text { Absent }\end{array}$ & $\begin{array}{c}\text { Turbid } \\
\text { water in the } \\
\text { classified } \\
\text { image }\end{array}$ & Total \\
\hline $\begin{array}{l}\text { Hydro- } \\
\text { Quebec }\end{array}$ & 51 & 0 & 12 & 63 \\
\hline $\begin{array}{l}\text { CHCRP } \\
\text { Field } \\
\text { Team }\end{array}$ & 31 & 35 & 18 & 84 \\
\hline Total & 82 & 35 & 36 & 147 \\
\hline
\end{tabular}

Table 2. Number of ground-truth data points coming from each dataset for a) the present eelgrass class; b) the absent eelgrass class, and c) the turbid water class

\subsection{Image Processing}

The four images obtained from the USGS Earthexplorer were top-of-atmosphere (TOA) reflectance images that were converted into surface reflectance images using Acolite, a free atmospheric correction software by the Royal Belgian Institute of Natural Sciences designed for simple and fast processing of coastal scenes (Vanhellemont, Ruddick, 2018). The atmospheric correction in the Acolite software is based on the dark-spectrum 
fitting algorithm, and a sun glint correction is also applied during the correction (Vanhellemont, 2019). Acolite was also used to mosaic the three images acquired on September 16, 2019. Once processing was completed, the resulting image mosaic was clipped to the coastline. The September image mosaic produced by Acolite can be seen in Figure 2.

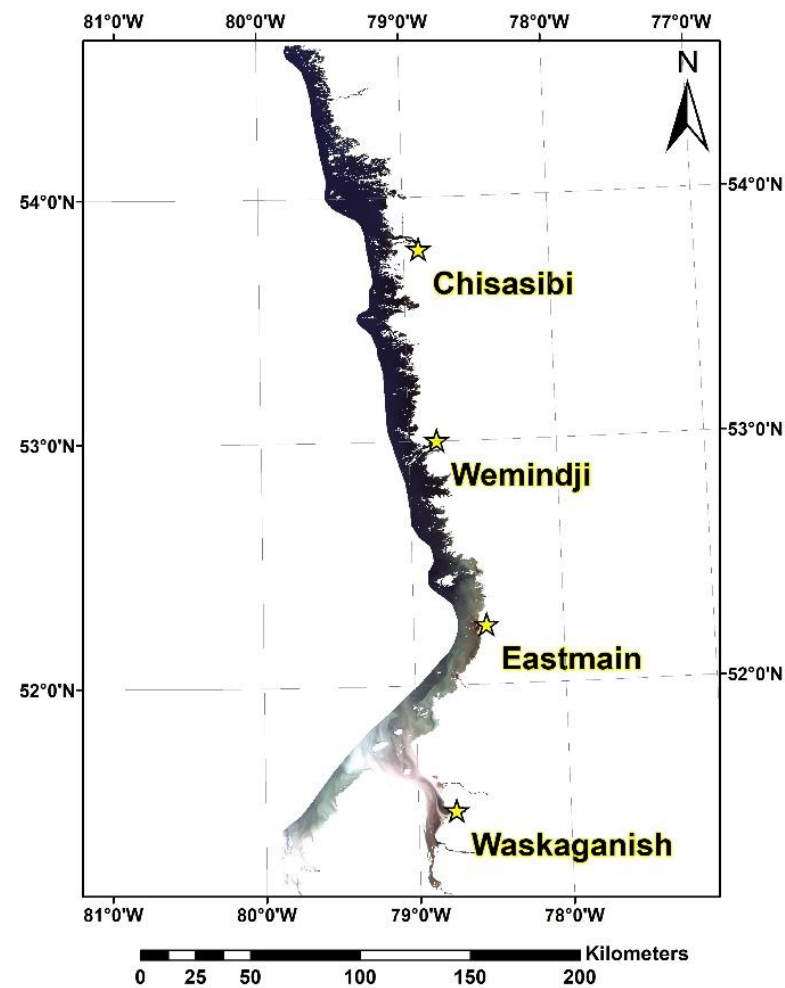

Figure 2. RGB composite for the mosaic created using Acolite with the images acquired over James Bay on September 16, 2019.

\subsection{Training Areas}

Both the September mosaics and the August imagery were classified using the Random Forests supervised classifier, which requires training areas. Representative training areas were delineated through photointerpretation of the satellite imagery for the four following classes: Eelgrass (EG), Turbid Water (TW), Highly Turbid Water (HTW), Optically Deep Water (DW). Spectral separability between representative training classes was assessed using Jeffries-Matusita (J-M) distance computed using Geomatica (Sen et al., 2019) the late summer of 2019, much of the eastern coastline of James Bay contained turbid water, either within bays near the coastline or out in deeper waters in the southern end of the bay (as exhibited in Figure 2). To account for this turbidity, a "Turbid Water" class was created through a manual selection of visibly turbid waters. Another class was created as "Highly turbid water", which encompasses the reflectance signal of optically shallow sandy James Bay waters as well as visually highly turbid waters (water that appeared very light brown or red on RGB imagery). Optically shallow sandy waters showed a similar spectral curve to highly turbid waters, and both highly turbid waters and optically shallow waters displayed higher reflectance values than any other class in every visible band as well as the near-infrared band. To avoid conflating the two classes, these classes were merged. Besides, the deep-water class was meant to encompass all optically deep water that theoretically should not contain eelgrass.

\subsection{Additional Input Layers}

To bolster the potential separability between the four training classes, additional layers were created as inputs for the classifier. Acolite provides the option to compute the so-called "L2W Parameters", which include: Turbidity (Dogliotti et al., 2015), Suspended Material Concentration (Nechad et al., 2010), Floating Algal Index (Dogliotti et al., 2018), and Orange reflectance (Castagna et al., 2020). The four layers are computed during the atmospheric correction. Additionally, we used 11 vegetation indices as shown in Table 3. Finally, to separate optically deep-water areas, four bathymetric ratios were computed (Table 3 ). They are based on the ratio decay algorithm designed for evaluating satellite-derived bathymetry (Stumpf et al., 2003). The computed layers were combined with the surface reflectance mosaic from Acolite and used as inputs for the RF classifier.

\begin{tabular}{|c|c|}
\hline Variable & Expression* \\
\hline DVI & $\mathrm{NIR}-\mathrm{R}$ \\
GDVI & $\mathrm{NIR}-\mathrm{G}$ \\
GNDVI & $(\mathrm{NIR}-\mathrm{G}) /(\mathrm{NIR}+\mathrm{G})$ \\
NDVI & $(\mathrm{NIR}-\mathrm{R}) /(\mathrm{NIR}+\mathrm{R})$ \\
NG & $\mathrm{G} /(\mathrm{NIR}+\mathrm{R}+\mathrm{G})$ \\
NR & $\mathrm{R} /(\mathrm{NIR}+\mathrm{R}+\mathrm{G})$ \\
NNIR & $\mathrm{NIR} /(\mathrm{NIR}+\mathrm{R}+\mathrm{G})$ \\
RVI & $\mathrm{NIR} / \mathrm{R}$ \\
GRVI & $\mathrm{NIR} / \mathrm{G}$ \\
NDAVI & $(\mathrm{NIR}-\mathrm{B}) /(\mathrm{NIR}+\mathrm{B})$ \\
WAVI & $1.5 *(\mathrm{NIR}-\mathrm{B}) /(\mathrm{NIR}+\mathrm{B}+0.5)$ \\
Bathy 1 & $\mathrm{Ln}(\mathrm{B} / \mathrm{G})$ \\
Bathy 2 & $\mathrm{Ln}(\mathrm{Ub} / \mathrm{G})$ \\
Bathy 3 & $\mathrm{Ln}(\mathrm{B} / \mathrm{R})$ \\
Bathy 4 & $\mathrm{Ln}(\mathrm{Ub} / \mathrm{R})$ \\
\hline
\end{tabular}

Band $(0.630-0.680 \mu \mathrm{m})$ reflectance, $G=$ Green Band $(0.525$ $0.600 \mu \mathrm{m})$ reflectance, $B=$ Blue Band $(0.450-0.515 \mu \mathrm{m})$ reflectance, $U b=$ Ultrablue Band $(0.433-0.453 \mu \mathrm{m})$ reflectance.

Table 3. Input variables added to the classifier.

\subsection{Random Forests Classifier}

The classifier that was used is Random Forests, a non-parametric, decision-tree classifier that does not assume a normal distribution of the input data (Breiman, 2001). Random Forests can be run in two ways: "all-polygon" and "sub-polygon". The all-polygon setting uses all the pixels within the training area polygons, while the sub-polygon version randomly selects a user-determined number of pixels from each training area polygons. For this study, the all-polygon setting was used, as it has the advantage of taking account of the actual class size. The forest size was 500 independent decision trees. The mtry variable, which refers to the number of variables randomly sampled as candidates at each split of every node, was set to the default value (the square root of the total number of predictor variables, rounded down). The classifier randomly selects two-thirds of the training data (referred to as "In Bag" data) to develop one decision tree. This tree is then validated using the remaining third of the training data (referred to as "out of bag" data). The process is repeated for the 500 individual decision trees and produces 500 independent classifications. These independent classifications are then combined to create the final classification. RF is not sensitive to noise or over-fitting and can estimate the importance of the individual input variables. The August image was classified separately from the September mosaic and the area covered by clouds was clipped from the August classified image and 
mosaicked together on the September image to create one classified image mosaic. The classification accuracy assessment and the ground-truth validation accuracy assessment use the combined data from both image classifications.

\section{RESULTS}

\subsection{Class Separability}

Training areas were delineated for each class (Eelgrass, Turbid Water, Highly Turbid Water, Clear Water) from the image mosaic on September 16 as well as the image obtained on August 26,2019 . They were used to compute mean values for each class to assess the class separability in the case of the first 6 Landsat- 8 bands (Figure 3), the Acolite variables (Figures 4), the vegetation indices (Figure 5), and the bathymetric ratios (Figure 6).

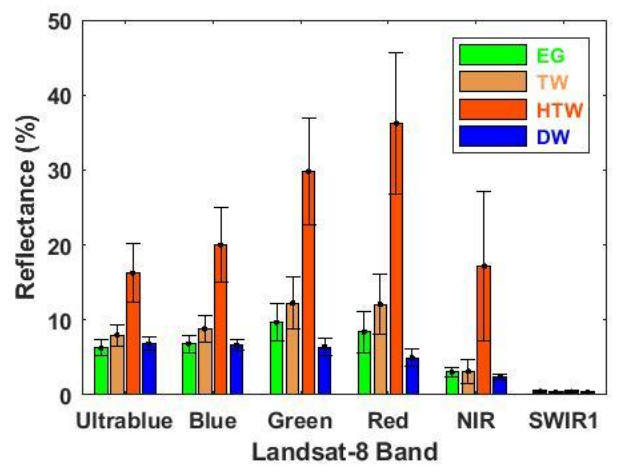

Figure 3. Mean reflectance values for each class for the first 6 Landsat- 8 bands for both images
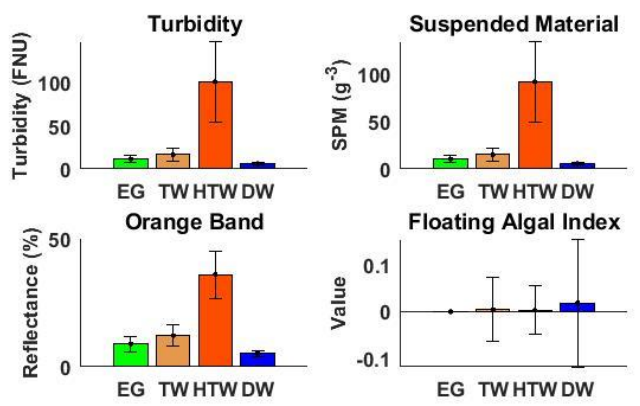

Figure 4. Mean values of the Acolite variables computed during the atmospheric correction for each class for both images

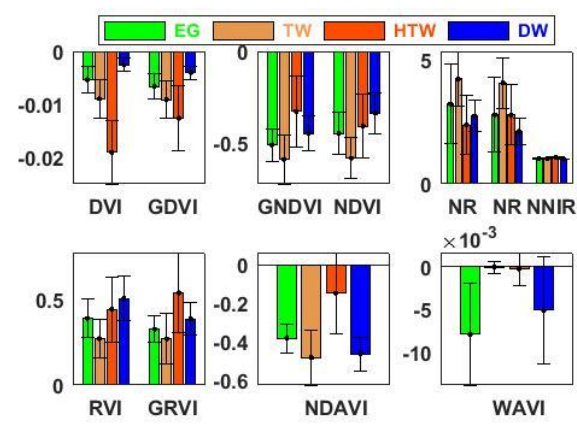

Figure 5. Mean values of the vegetation indices used in the study for each class for both images

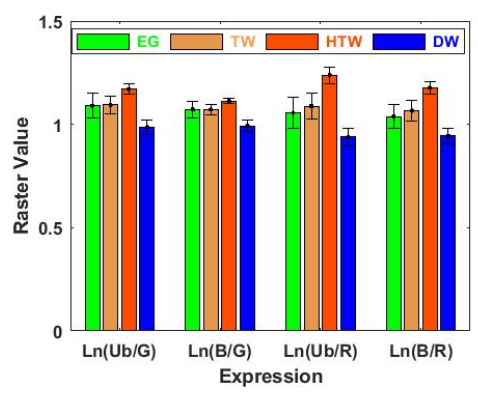

Figure 6. Mean values of each bathymetric ratio for each class for both images

The training areas of the September image were also used to assess the class spectral separability using the J-M distance computed with the 6 first Landsat- 8 OLI bands (Table 4).

\begin{tabular}{|c|c|c|c|}
\hline Class Code & EG & TW & HTW \\
\hline TW & 1.341 & - & - \\
\hline HTW & 1.986 & 1.939 & - \\
\hline DW & 1.388 & 1.674 & 1.999 \\
\hline
\end{tabular}

Table 4. J-M distances computed with the class training areas for the Landsat- 8 OLI bands for the September image mosaic.

\subsection{Classification}

The September 16 and August 26 images were then classified in $\mathrm{R}$ using the Random Forests classifier (R Core Team, 2013), using the 6 first Landsat- 8 OLI bands and all variables listed in Table 3. The confusion matrix assessing the out-of-bag training areas within the classifier was combined for both images and is presented in Table 5. The classification accuracy is high, with an overall accuracy of $99.3 \%$. The classified image is shown in Figure 7. Detailed maps were created at a resolution of 1:250,000 around each of the main Cree coastal communities: Chisasibi (Figure 8), Wemindji (Figure 9), Eastmain (Figure 10), and Waskaganish, (Figure 11).

\begin{tabular}{|l|c|c|c|c|c|c|}
\hline Class & EG & TW & HTW & CW & Total & UA (\%) \\
\hline EG & $\mathbf{3 1 3 9}$ & 56 & 43 & 268 & 3506 & 89.5 \\
\hline TW & 28 & $\mathbf{3 3 1 2 9}$ & 78 & 197 & 33432 & 99.1 \\
\hline HTW & 58 & 55 & $\mathbf{9 6 6 8 8}$ & 65 & 96866 & 99.8 \\
\hline CW & 69 & 274 & 74 & $\mathbf{3 7 8 6 6}$ & 38283 & 98.9 \\
\hline Total & 3294 & 33514 & 96883 & 38396 & $\mathbf{1 7 2 0 8 7}$ & \\
\hline $\begin{array}{l}\text { PA } \\
(\%)\end{array}$ & 95.3 & 98.9 & 99.8 & 98.7 & & $\begin{array}{c}\text { OA }= \\
99.3 \%\end{array}$ \\
\hline
\end{tabular}

Table 5. Confusion matrix for out-of-bag training pixels computed with the Random Forests classifier (bold values represent well-classified pixels)

The classified image was then assessed for accuracy by comparing the mapped eelgrass presence/absence to the field dataset provided by Hydro-Quebec and the project's field research team. Points that were classified as turbid water were excluded from the validation analysis. We achieved an overall accuracy of $78.7 \%$ (Table 6). The eelgrass present class resulted in a User's accuracy of $84.2 \%$ and a Producer's accuracy of $87.3 \%$, which are excellent considering the challenging environmental conditions. 


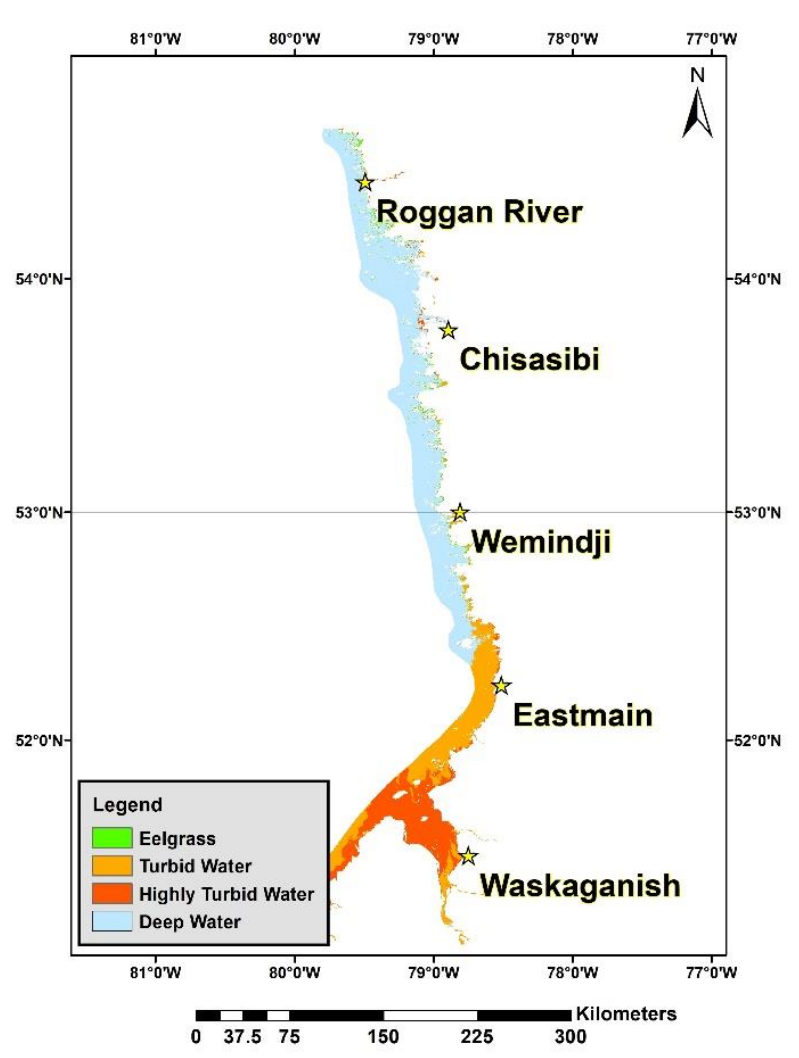

Figure 7. Classified image produced by applying the Random Forests classifier to both Landsat-8 OLI images.

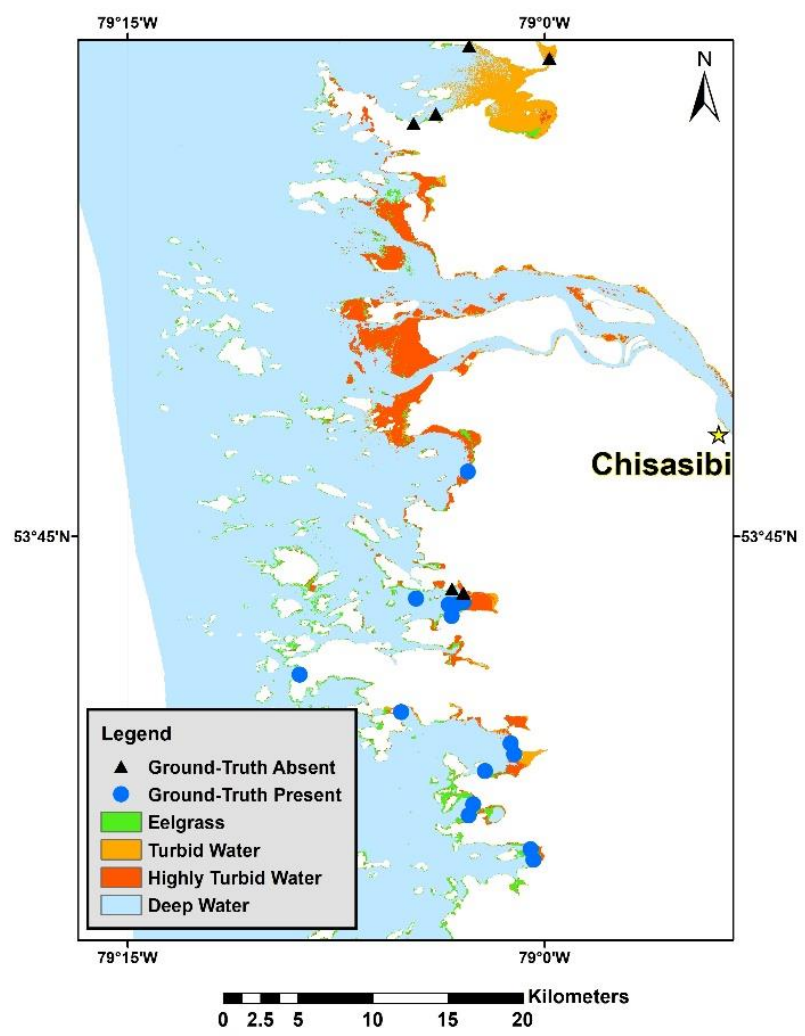

Figure 8. Classified image produced by applying the Random Forests classifier to both Landsat-8 OLI images for the coastline around Chisasibi.

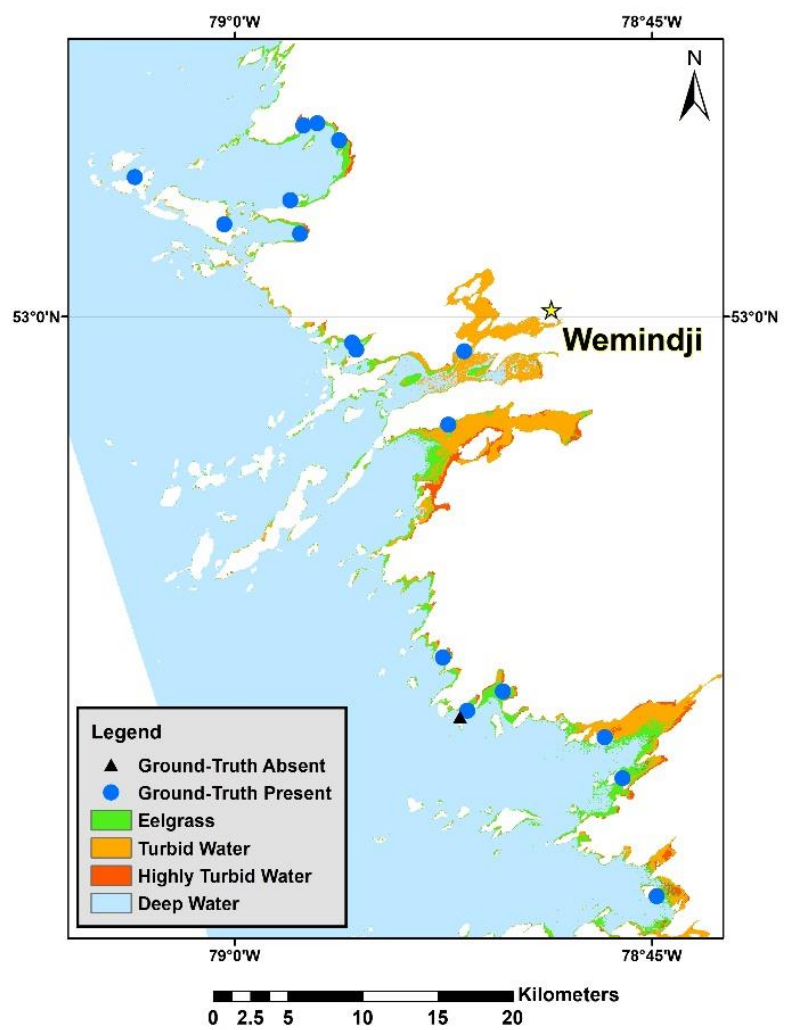

Figure 9. Classified image produced by applying the Random Forests classifier to both Landsat-8 OLI images outlining the coastline around Wemindji.

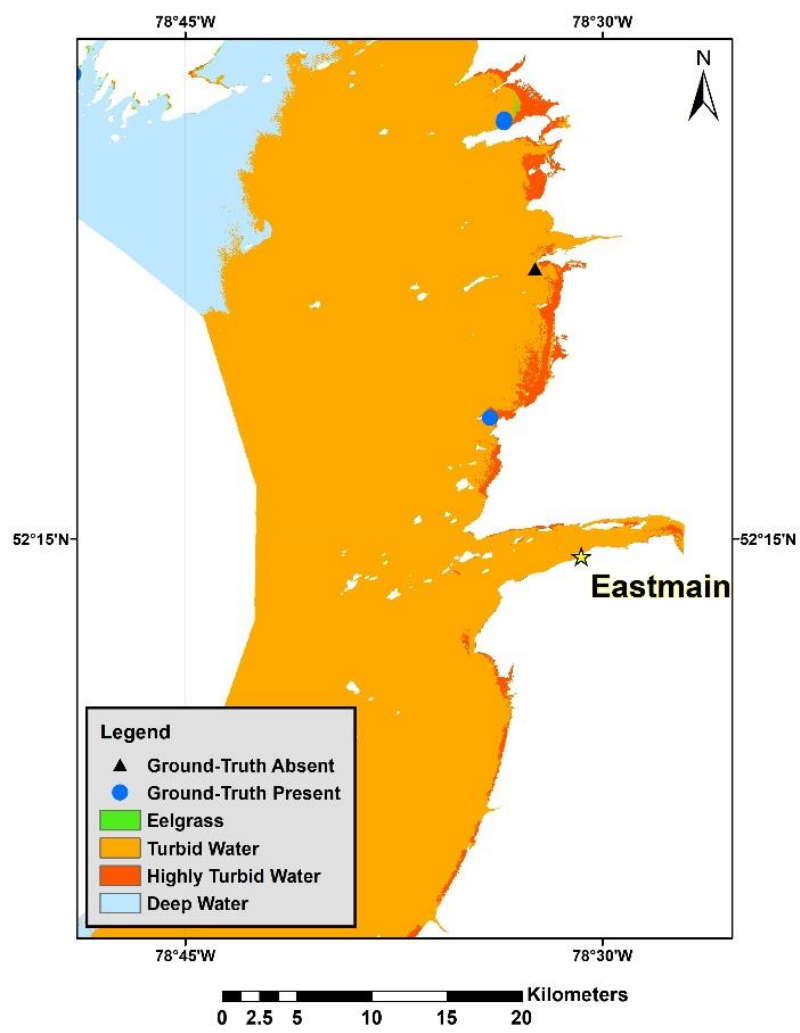

Figure 10. Classified image produced by applying the Random Forests classifier to both Landsat-8 OLI images outlining the coastline around Eastmain. 


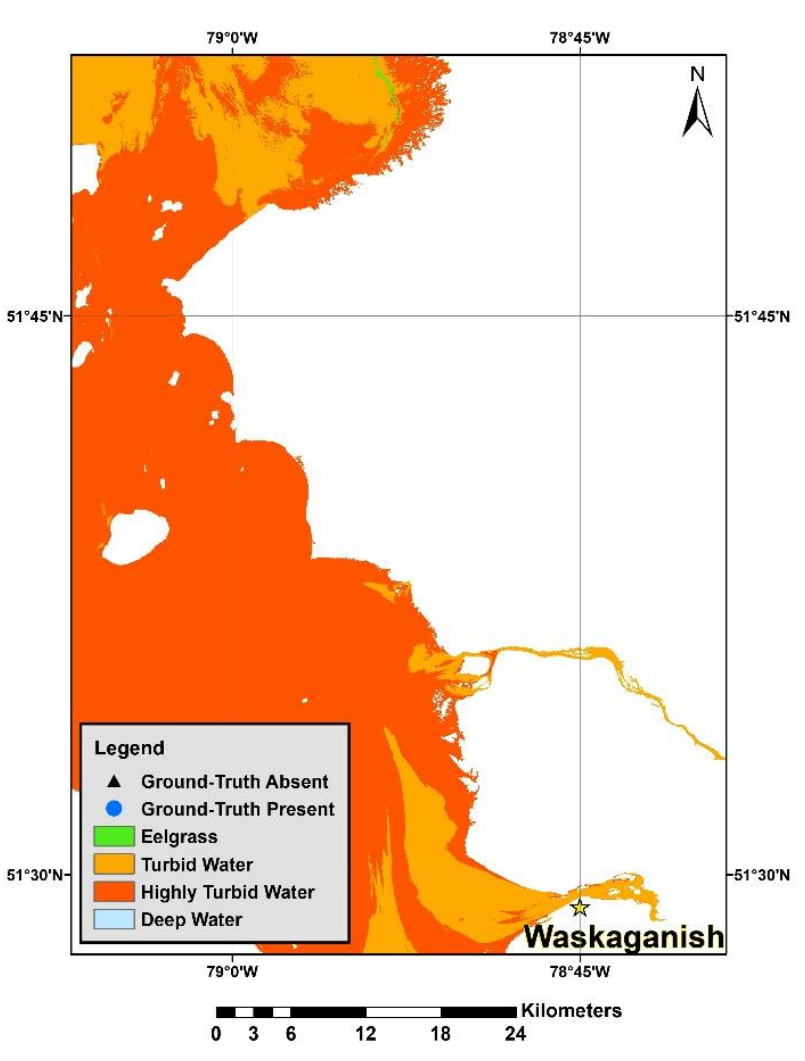

Figure 11. Classified image produced by applying the Random Forests classifier to both Landsat-8 OLI images outlining the coastline around Waskaganish.

\begin{tabular}{|c|c|c|c|c|}
\hline Class & Present & Absent & Total & UA (\%) \\
\hline Present & 69 & 13 & 82 & 84.2 \\
\hline Absent & 10 & 16 & 26 & 61.5 \\
\hline Total & 79 & 29 & 108 & OA $=78.7 \%$ \\
\cline { 1 - 3 } PA (\%) & 87.3 & 55.2 & & \\
\hline
\end{tabular}

Table 6. Validation accuracies obtained by comparing fieldbased ground-truth sites with the classified image (bold figures indicated well-mapped sites)

\section{DISCUSSIONS AND CONCLUSIONS}

Our study presents preliminary results on combining local indigenous knowledge and Landsat-8 OLI imagery for mapping eelgrass beds in water with high turbidity. The imagery was atmospherically corrected using the Acolite software. We show that eelgrass can be spectrally distinguished from optically deep and turbid waters. The spectral signature of eelgrass was not shown to be detectable underneath suspended material in the water column since the red and green reflectance of turbid waters is dominated by particulate matter in the water column. The overall accuracy for the validation was $78.70 \%$. The addition of extra input layers to the Landsat-8 OLI reflectance bands improved the validation accuracy significantly. Decreasing or optimizing layers was shown not to increase the validation overall accuracy, and thus it is recommended to add these additional input layers to improve the accuracy of Landsat- 8 classifications.
Our classified image mosaics did not show extensive eelgrass beds where it was possible to map them with the Landsat8-OLI imagery. Such observations agree with the Cree Land Users of Eeyou Istchee who have noted steady declines in eelgrass coverage along the coast in the late 1980s and then a drastic decline in 1997-1998 (Consortium Genivar Waska, 2017). Cree reported that since the decline in the late $1990 \mathrm{~s}$, the recovery of the eelgrass has been very slow. Such a study is therefore a good example of how local indigenous knowledge can be combined with Western science in a case study.

Landsat-8 imagery, while providing exceptional temporal coverage, is limited in its spatial resolution. The $30 \mathrm{~m}$ pixel size of Landsat- 8 imagery limits the creation of training areas to only large beds that dominate the reflectance signal of a single pixel. The use of Landsat- 8 imagery may therefore not be suitable for classifying patchier eelgrass or smaller patches of turbid/clear water. The $30 \mathrm{~m}$ spatial resolution also makes an accurate location of the coastline difficult. This was not too much of an issue in James Bay, where optically shallow waters suitable for eelgrass extend far past the coastline-however it could present an issue if applied to a coastline with only a small strip $(<30 \mathrm{~m}$ width) of shallow enough water for eelgrass growth. Besides, while James Bay contains geographically large eelgrass beds, areas dominated by other types of submerged aquatic vegetation may have similar spectral characteristics. Therefore, this study framework may not be applicable for locations where multiple submerged aquatic vegetation may encompass a geographic area larger than $30 \mathrm{~m}$. While this study provided a framework for mapping eelgrass beds on a large spatial scale in turbid waters, more work should be done researching the accuracy of the Random Forests classifier on smaller spatial scales using higher resolution imagery. Sentinel-2 imagery could potentially offer bay-wide coverage at a $10 \mathrm{~m}$ resolution and should be explored as a high-resolution multispectral alternative. High-resolution hyperspectral imagery would be a suitable option for mapping sections of the Bay, but the unpredictable bay-wide turbidity could also make hyperspectral imagery acquisition costly or not feasible.

Lastly, substituting true bathymetry data for the ratio decay algorithms used in this study may improve classification; however, in the absence of bathymetry data, the high spectral separability between deep clear water and eelgrass makes the bathymetric ratios a good alternative as a classifier input. Our classified image was validated against 108 points and there is the need to add more validation points in further work.

\section{ACKNOWLEDGMENTS}

The authors would like to thank the people of the Cree coastal communities of Wemindji (particularly Geraldine Mark) and Chisasibi for helping us get out on the bay and perform field research. We would also like to thank the Niskamoon Corporation and Mitacs for their generous funding for this project, as well as Hydro-Quebec and the CHCRP eelgrass health team for their field data set used to verify the classified maps.

\section{REFERENCES}

Bos, A.R., Bouma, T.J., de Kort, G.L.J., van Katwijk, M.M., 2007. Ecosystem engineering by annual intertidal seagrass beds: Sediment accretion and modification. Estuar Coast Shelf S, 74(1-2), 344-348. https://doi.org/10.1016/j.ecss.2007.04.006 
Castagna, A., Simis, S., Dierssen, H., Vanhellemont, Q., Sabbe, K., Vyverman, W., 2020. Extending Landsat 8: Retrieval of an orange contra-band for inland water quality applications. Remote Sensing, 12(4), 637. https://doi.org/10.3390/rs12040637

COMEX, 2013. Report on the Public Consultations held in November 2012, following implementation of HydroQuebec's Eastmain-1-A and Sarcelle Powerhouses and Rupert Diversion Project. 238 p., https://comexqc.ca/wpcontent/uploads/Rapport-EM1A-COMEX_EN_web.pdf

Consortium Genivar Waska, 2017. Eastmain-1-A and Sarcelle Powerhouses and Rupert Diversion. Followup of eelgrass beds on the Northeast Coast of Baie James (James Bay) Study Report 2014. Report prepared by Consortium GENIVAR-Waska for Hydro-Québec Production, 83 pages + appendices

Department of Fisheries and Oceans (DFO), 2009. Does eelgrass (Zostera marina) meet the criteria as an ecological significant species? DFO Can Sci Advis Sec Sci Advis Rep 2009:1-11

Dignard, N., Lalumière, R., Reed, A., Julien, M., 1991. Habitats of the northeast coast of James Bay. Environment Canada, Canada Wildlife Service, 36 pages.

Dogliotti, A., Gossn, J., Vanhellemont, Q., Ruddick, K., 2018. Detecting and quantifying a massive invasion of floating aquatic plants in the Río de la Plata turbid waters using high spatial resolution ocean color imagery. Remote Sensing, 10(7), 1140. https://doi.org/10.3390/rs10071140

Dogliotti, A.I., Ruddick, K.G., Nechad, B., Doxaran, D., Knaeps, E., 2015. A single algorithm to retrieve turbidity from remotely-sensed data in all coastal and estuarine waters. Remote Sens Environ, 156, 157-168. https://doi.org/10.1016/j.rse.2014.09.020

El-Sabh, M.I., Koutitonsky, V.G., 1977. An oceanographic study of James Bay before the completion of the La Grande Hydroelectric Complex. Arctic, 30(3), 169-186. https://doi.org/10.14430/arctic2697

Hydro-Québec: Englobe corporation. 2019. Rapport de mission Suivi de la zostère marine de la côte nord-est de la baie James. Rapport préparé pour Hydro-Québec, Montréal, Quebec.

Joseph, V., Schmidt, A., Gregory, R., 2013. Use of eelgrass habitats by fish in eastern Canada. DFO Can. Sci. Advis. Sec. Res. Doc. 2012/138. ii + 12p. www.dfompo.gc.ca/csas-sccs/

Kennedy, L.A., Juanes, F., El-Sabaawi, R., 2018. Eelgrass as valuable nearshore foraging habitat for juvenile Pacific Salmon in the early marine period. Mar Coast Fishs, 10(2), 190-203. https://doi.org/10.1002/mcf2.10018

Kollars, N.M., Henry, A.K. Whalen, M.A., Boyer, K.E., Cusson, M., Eklöf, J.S., Hereu, C M., Jorgensen, P., Kiriakopolos, S.L., Reynolds, P.L., Tomas, F., Turner, M.S., Ruesink J.L., 2017. Meta-analysis of reciprocal linkages between temperate seagrasses and waterfowl with implications for conservation. Front Plant Sci, 8 , Article 2119, doi: 10.3389/fpls.2017.02119
Lalumière, R., Messier, D., Fournier J.-J., McRoy, P.C.,1994. Eelgrass meadows in a low arctic environment, the northeast coast of James Bay, Québec. Aquat Bot 47, 303-315

Macreadie, P.I., Baird, M.E., Trevathan-Tackett, S.M, Larkum, A.W.D., Ralph, P.J., 2014. Quantifying and modelling the carbon sequestration capacity of eelgrass meadows A critical assessment. Mar Pollut Bull, 83(2), 430-439.

Martini, I.P., 1986. Chapter 7. Coastal features of Canadian inland seas. Elsevier Oceanography Series, 44, 117-142.

Marsh, J. H. (2015). James Bay Project. The Canadian Encyclopedia. https://www.thecanadianencyclopedia.ca/en/article/james -bay-project

Murphy, R., Orzetti, L., Johnson, W., 2011. Plant fact sheet for eelgrass (Zostera marina). USDA, Natural Resources Conservation Service, Norman A. Berg National Plant Materials Center. Beltsville, MD, http://www.nrcs.usda.gov/

Nechad, B., Ruddick, K.G., Park, Y., 2010. Calibration and validation of a generic multisensor algorithm for mapping of total suspended matter in turbid waters. Remote Sens Environ, 114(4), 854-866. https://doi.org/10.1016/j.rse.2009.11.022

Nienhuis, P.H., Groenendijk, A.M., 1986. Consumption of eelgrass (Zostera marina) by birds and invertebrates: an annual budget. Mar. Ecol. Prog. Ser., 29, 29-35.

O'Connor, M., Noisette, F., Davis, Leblanc, M.L., Richer, L. 2019. Eelgrass monitoring surveys - Coastal Comprehensive Habitat Program (unpublished data).

O’Neill, J., Costa, M., 2013. Mapping eelgrass (Zostera marina) in the Gulf Islands National Park Reserve of Canada using high spatial resolution satellite and airborne imagery. Remote Sens Environ, 133, 152-167.

Potouroglou, M., Bull, J.C., Krauss, K.W., Kennedy, H.A., Fusi, M., Daffonchio, D., Mangora, M.M., Githaiga, M.N., Diele, K., Huxham, M., 201). Measuring the role of seagrasses in regulating sediment surface elevation. Scientific Reports, 7(1), 1-11. https://doi.org/10.1038/s41598-017-12354-y

R Core Team, 2013. R: A language and environment for statistical computing. R Foundation for Statistical Computing, Vienna, Austria. URL http://www.Rproject.org/.

Reshitnyk, L., Costa, M., Robinson, C., Dearden, P., 2014. Evaluation of WorldView-2 and acoustic remote sensing for mapping benthic habitats in temperate coastal Pacific waters. Remote Sens Environ, 153, 7-23.

Royer, M.-J. S. (2016). Eastern James Bay and the Cree. In M.J. S. Royer (Ed.), Climate, Environment and Cree Observations: James Bay Territory, Canada (pp. 35-61). Springer International Publishing. https://doi.org/10.1007/978-3-319-25181-3_3 
Sen, R., Goswami, S., Chakraborty, B., 2019. Jeffries-Matusita Distance as a Tool for Feature Selection. 2019

International Conference on Data Science and Engineering, ICDSE 2019, 15-20. Institute of Electrical and Electronics Engineers Inc. https://doi.org/10.1109/ICDSE47409.2019.8971800

Seymour, N.R., Miller, A.G., Garbary, D.J., 2002. Decline of Canada geese (Branta canadensis) and common goldeneye (Bucephala clangula) associated with a collapse of eelgrass (Zostera marina) in a Nova Scotia estuary. Helgol Mar Res 56, 198-202.

Stumpf, R.P., Holderied, K., Sinclair M., 2003. Determination of water depth with high-resolution satellite imagery over variable bottom types. Limnol Oceanogr 48(1 II), 54756.

Taha, W, Bonneau-Lefebvre M, Cueto Bergner A, Tremblay A., 2019. Evolution from past to future conditions of fast ice coverage in James Bay. Front Erath Sci, 7, Article 254.

Vanhellemont, Q., 2019. Adaptation of the dark spectrum fitting atmospheric correction for aquatic applications of the Landsat and Sentinel-2 archives. Remote Sens Environ, 225, 175-192. https://doi.org/10.1016/j.rse.2019.03.010

Vanhellemont, Q., Ruddick, K., 2018. Atmospheric correction of meter-scale optical satellite data for inland and coastal water applications. Remote Sens Environ, 216, 586-597. https://doi.org/10.1016/j.rse.2018.07.015

Waycott, M., Duarte, C.M., Carruthers, T.J.B., Orth, R.J., Dennison, W.C., Olyarnik, S., Calladine, A., Fourqurean, J.W., Heck Jr., K.L., Hughes, A.R., Kendrick, G.A., Kenworthy, W.J., Short, F.T., \& Williams, S.L., 2009. Accelerating loss of seagrasses across the globe threatens coastal ecosystems. P Natl Acad Sci USA, 106 (30), 12377-12381.

Wong, M.C., Bravo, M.A., Dowd, M., 2013. Ecological dynamics of Zostera marina (eelgrass) in three adjacent bays in Atlantic Canada. Bot Mar, 56(5-6), 413-424. https://doi.org/10.1515/bot-2013-0068 